\title{
BIOLOGIA DO ÀCARO PREDADOR Amblyseius herbicolus ALIMENTADO POR PÓLEN E PELA PRESA Tetranychus urticae
}

\section{BIOLOGY OF THE PREDATORY Amblyseius herbicolus MITE (Acari: Phytoseiidae) FEEDS ON POLLEN AND ON Tetranychus urticae}

\author{
Hamilton Olivera, Marcos A. Fandini, Daniela Rezende, Alberto Soto, Katherine Girón, \\ Hermes Araméndiz y Angelo Pallini \\ Hamilton Oliveira ${ }^{1}$, Marcos A.M. FAdini $^{2}$, DANiEla Rezende ${ }^{3}$, Alberto Soto \\ GIRALDO $^{4}$, Katherine Girón Pérez ${ }^{5}$; HeRmes ARAMENDIZ ${ }^{6}$, ANGELO PALLINI ${ }^{3}$,
}

\begin{abstract}
RESUMO
Em levantamentos populacionais realizados em cultivos de morangueiro, Amblyseiu. herbicolus foi encontrado em plantas infestadas pelo ácaro fitófago Tetranychus urticae Koch (Acari: Tetranychidae). Por ser T. urticae a principal praga da cultura do morangueiro, existe uma busca constante de novas espécies com potencial de agente de controle biológico contra esse fitófago. Desse modo, o objetivo desse trabalho foi avaliar a biologia do ácaro predador A. herbicolus quando alimentado por dietas compostas por pólen de mamona, por T. urticae e pela associação de pólen de mamona e $T$. urticae. Essas dietas constituíram os tratamentos do experimento que foi conduzido sob condições controladas $\left(\mathrm{T}=25 \pm 2^{\circ} \mathrm{C}\right.$, UR $=65 \pm 10 \%$ e Fotoperíodo de 13h) sobre arenas confeccionadas com folhas de morangueiro $(\varnothing=2.5 \mathrm{~cm})$. Os resultados demonstram que a fase juvenil do ácaro predador A. herbicolus se completa apenas quando o mesmo foi alimentado por pólen e por pólen e $T$. urticae. A maior longevidade do predador foi observada quando o mesmo foi alimentado pela dieta composta apenas por pólen, porém maior taxa de oviposição foi observada quando A. herbicolus foi alimentado pela associação das dietas de pólen e T. urticae. Os dados obtidos demonstram que o ácaro predador $A$. herbicolus atinge a fase adulta somente quando alimentado por dietas contendo pólen. Porém, na fase adulta, $A$. herbicolus necessita se alimentar de dietas à base de T. urticae para obter maior energia e assim, conseqüentemente apresentar maior potencial reprodutivo.
\end{abstract}

Palavras - chave: Alimento alternativo, morangueiro, longevidade, potencial reprodutivo, controle biológico.

In population risings accomplished in strawberry plant cultivations, A. herbicolus was found in plants infested by the two-spotted mite Tetranychus urticae Koch (Acari: Tetranychidae). T. urticae is the main curse strawberries' plants, exists a constant search of new species with potential agent of biological control against that phytophagous. This way, the objective of that work was to evaluate the biology of the predaceous mite A. herbicolus when fed by diets composed by castor oil plant pollen, $T$. urticae and the association of castor oil plant pollen and T. urticae. Those diets constituted the treatments of the experiment that it was driven under controlled conditions $\left(\mathrm{T}=25 \pm 2^{\circ} \mathrm{C}, \mathrm{RH}=65 \pm 10 \%\right.$ and photoperiod 13:00h (L:D) on arenas made with strawberries' leaves $(\varnothing=2.5 \mathrm{~cm})$. The results demonstrated that the juvenile phase of the predaceous mite A. herbicolus is just completed when the same was fed by pollen and by pollen and $T$. urticae. The largest longevity of the predator was observed when the same was fed by the diet composed just by pollen, however larger oviposition tax was observed when A. herbicolus was fed by the association of the pollen diets and T. urticae. 
The obtained data demonstrated that the predaceous mite $A$. herbicolus reaches the adult phase only when fed by diets containing pollen. However, in the adult phase, A. herbicolus needs if it feeds from diets to the base of T. urticae to obtain larger energy and like this, consequently to present reproductive potential adult.

Key words: Alternative food, strawberry plant, longevity, reproductive potential, biological control.

${ }^{1}$ Corporacion Colombiana de Investigación Agropecuaria - Corpoica. C.I. Turipanà. Km 13, Via Monteria Cereté. hgomes@corpoica.org.co,

${ }^{2}$ Universidade Federal de São João Del-Rei, Brasil, marcosfadini@gmail.com

${ }^{3}$ Universidad Federal de Vicosa, Brasil. daniagroufv@hotmail.com.br, pallini@ufv.br

${ }^{4}$ Universidad de Caldas, asotog@hotmail.com

${ }^{5}$ Maestra en Entomología, entomologa@ymail.com

${ }^{6}$ Universidad de Córdoba, haramendiz@hotmail.com

\section{INTRODUÇÃO}

O acáro-rajado Tetranychus urticae Koch (Acari: Tetranychidae) é uma das mais importantes pragas de muitas culturas em regiões de climas temperado e tropical (Skirvin y Williams 1999, Garcia-Marí y Gonzalez-Zamora 1999). Este ácaro-rajado pode colonizar mais de 600 espécies de plantas, desde a emergência das mesmas até a fase de produção, chegando também, em muitos casos, a atacar flores e frutos, sendo que os surtos populacionais normalmente ocorrem ainda no período de crescimento das plantas (Badii et al. 2004). A população de ácaro-rajado pode crescer acima de $40 \%$ ao dia. Esse crescimento populacional exponencial normalmente termina abruptamente devido à super exploração do material vegetal atacado, porém neste momento o prejuízo sofrido pelo produtor já alcança os $100 \%$ de prejuízo (Krips et al. 1998).

O controle químico é o principal método de combate utilizado contra o ácaro-rajado. Entretanto, devido ao uso excessivo dos pesticidas e aos problemas associados à resistência e à poluição ambiental tem aumentado a demanda por métodos de controle sustentáveis. O controle biológico do ácaro-rajado pode ser considerado um método alternativo ao controle 
químico. Diversas espécies de inimigos naturais têm sido publicadas como predadoras do ácaro-rajado. Estudos continuam a serem realizados em diferentes países para avaliar o potencial de inimigos naturais para controlar essa praga sem o uso de pesticidas e de modo a evitar a ocorrência de danos econômicos às culturas (Opit et al. 2005).

Ácaros predadores da família Phytoseiidae têm recebido grande atenção devido ao seu potencial como agentes reguladores de populações de ácaros fitófagos (Helle y Sabelis 1985, McMurtry y Croft 1997, Moraes 2002) e de pequenos insetos como mosca branca e tripes (Van Houten et al. 1995, Ali 1998). Em diversos países da Europa e América do Norte o controle de ácaros fitófagos em cultivos, principalmente em casa de vegetação, tem sido comumente realizado através da liberação de ácaros predadores da família Phytoseiidae (Osborne et al. 1985, Zhang y Sanderson 1995). Dentre esses, destaca-se o gênero Phytoseiulus que tem como alimento básico ácaros da família Tetranychidae (McMurtry y Croft 1997). Esse gênero possui nove espécies conhecidas mundialmente pela eficácia das mesmas como predadoras (Moraes et al. 2004). Phytoseiulus persimilis Athias-Henriot (Acari: Phytoseiidae) é o ácaro predador mais estudado para aplicação em programas de controle biológico em países localizados em regiões de clima temperado (Osborne et al. 1985, Zhang y Sanderson 1995, Moraes 2002). Porém, em países de clima tropical, região essa cujo P. persimilis não é nativo, trabalhos têm sido desenvolvidos com o objetivo de avaliar o potencial de outros ácaros predadores, pois sob altas temperatura e umidade $P$. persimilis apresenta baixo desempenho adaptativa, provavelmente devido à baixa adaptabilidade desse predador às condições climáticas prevalecentes (Bakker et al. 1993).

Na América Latina já foram encontrados 55 espécies de ácaros predadores nativos da região, dentre esses se inclui o ácaro predador Amblyseius herbicolus Chant (Acari: Phytoseiidae) 
(Moraes 1991). No Brasil esse predador é encontrado em diversas culturas como, por exemplo, plantas de erva-mate Ilex paraguariensis St Hill (Aquifoliaceae) e plantas de cafeeiro (Reis 2007) e em cultivos de morangueiro em casa de vegetação associado a populações do ácaro fitófago Tetranychus urticae. A presença de A herbicolus sobre plantas de morangueiro pode representar uma alternativa adequada aos pesticidas que representam o modo de combate mais utilizado para o controle de populações de ácaros-rajados. Desse modo esse trabalho teve como objetivo estudar as variáveis biológicas de A. herbicolus e avaliar o potencial do mesmo como agente de controle de $T$. urticae. Também se avaliou a possibilidade de alimentar este predador com pólen de mamona (Ricinus communis).

\section{MATERIAL E MÉTODOS}

\section{Métodos de criação}

Plantas de morangueiro foram cultivadas em vasos de 2,5 L no interior de casa de vegetação (13-38 ${ }^{\circ} \mathrm{C}, 40$ - 60\% U.R. e fotoperíodo de 13 h). Parte das plantas foi mantida em gaiolas confeccionadas em estrutura de madeira circundada por tecido de organza. Desse modo, algumas plantas permaneceram em gaiolas sem o ataque de ácaros fitófagos. Outra parte das plantas foi utilizada para criação do T. urticae. Posteriormente as folhas de morangueiro infestadas foram destacadas e os adultos de T. urticae transferidos com auxilio de pincel para arenas de criação. Essas arenas foram confeccionadas com folhas de morangueiro colocadas sobre espumas (3.0 cm de espessura) dentro de bandejas plásticas (15 x 25 x $5 \mathrm{~cm}$ ) com folhas circundadas com algodão umedecido para evitar a fuga dos ácaros. O ácaro predador $A$. herbicolus foi originalmente coletado em plantas de morango e mantido em laboratório e alimentado com pólen de mamona (Ricinus communis) sobre arenas confeccionadas com discos de lâmina plástica flexível de cor preta, colocadas sobre espumas (4.0 cm de espessura) dentro de bandejas retangulares de PVC (30 X 20 cm). Para proporcionar uma fonte de água 
os ácaros, colocou-se um filete de água na bandeja e as bordas da arena foram suavemente cobertas com lenços de papel que tocavam o filete de água contido na bandeja o que proporcionou umidade. As arenas de criação foram mantidas em laboratório a $25 \pm 1{ }^{\circ} \mathrm{C}, 60 \pm$ 5\% de UR e fotoperíodo de 13 h, correspondendo às condições da região onde foram coletados os ácaros.

\section{Biologia de Amblyseius herbicolus com diferentes dietas}

O experimento foi constituído de três tratamentos correspondentes a uma dieta diferente, sendo: dieta 1 = pólen de mamona, dieta 2 = dez fêmeas de $T$. urticae no início do período reprodutivo e, dieta 3 = pólen de mamona + dez fêmeas $T$. urticae no início do período reprodutivo. Cada tratamento foi constituído de 30 repetições, sendo cada repetição constituída por arena confeccionada com placa de petri $(\varnothing=3,0 \mathrm{~cm}, \mathrm{~h}=1,5 \mathrm{~cm})$ que no interior da mesma foi colocado um disco de folha de morangueiro $(\varnothing=2,5 \mathrm{~cm})$. Para fixar o disco de folha morangueiro à placa de petri foi colocada no fundo dessa uma camada de ágar ( $\mathrm{h}=0,5 \mathrm{~cm}$ ). Ao esfriar o ágar foi recortado com o mesmo diâmetro do disco de morangueiro. O espaço formado entre o ágar e as bordas da placa de petri foi preenchido com água. Essa água serviu para manter a turgidez da folha de morangueiro, bem como funcionou como uma barreira ao escape dos ácaros fitófagos e predadores. Sobre cada arena foi colocado um ovo recém ovipositado de $A$. herbicolus. Simultaneamente as diferentes dietas avaliadas também foram colocadas sobre as arenas correspondentes aos respectivos tratamentos. Desse modo, quando as larvas de $A$. herbicolus eclodiram, nas arenas correspondentes às dietas 2 e 3, havia fêmeas e ovos de T. urticae. As avaliações foram realizadas a cada 24 h e foram coletados dados sobre mudança de estádio, duração dos estádios e sobrevivência dos ácaros. O estádio de protoninfa foi distinguido das larvas pelo seu número de pernas. Já as deutoninfas foram distinguidas das protoninfas pela presença de exúvia que após as leituras foram retiradas das 
arenas. Do mesmo modo, a presença de exúvias foi utilizada para distinguir adultos de protoninfa. Quando os ácaros predadores atingiram a fase adulta, casais originados da mesma dieta foram formados e transferidos para novas arenas. Outras observações foram realizadas durante os dias com o objetivo de observar o comportamento diário de A. herbicolus em relação as teias formadas por T. urticae. Os dados foram submetidos á ANOVA e posteriormente, quando necessário, submetidas ao Teste de Tukey $(\mathrm{P}=0,05)$.

\section{RESULTADOS E DISCUSSAO}

Como pode ser observado na figura 1 não houve diferença estatística para a longevidade do período juvenil quando $A$. herbicolus foi alimentado com as dietas um e três (ANOVA, $\operatorname{Pr}=$ 0,53; $\mathrm{F}=0,42)$. Já quando $A$. herbicolus foi alimentado com a dieta 2, o predador não completou sequer a fase larval. Quando comparada a longevidade das fases no período juvenil, houve diferença entre elas apenas para o período de larva quando A. herbicolus foi alimentado pelas dietas um e três (ANOVA, $\operatorname{Pr}=<0,05 ; \mathrm{F}=6,1$ ). O período de sobrevivência dos adultos de A. herbicolus foi significativamente superior quando esse predador foi alimentado com a dieta 1 em relação à dieta $3(\mathrm{~F}<0,05, \mathrm{p}=6,28)$. Porém, como pode ser observado na figura 2, mesmo vivendo por maior período quando alimentado pela dieta 1 , a oviposição diária de $A$. herbicolus foi superior para os indivíduos mantidos na dieta 3 $(\operatorname{Pr}=7,28 ; \mathrm{F}<0,05)$.

Várias espécies de Amblyseius spp representam a maior parte dos ácaros predadores de ácaros fitófagos em vários agroecossistemas (Shih y Huang 1991). Por ocupar um ecossistema tão amplo, é de se esperar que os predadores desse gênero apresentem uma grande variação em termos das presas das quais os mesmos se alimentam. Porém, quando mantido em arenas contendo apenas fêmeas adultas e ovos do ácaro-rajado, A. herbicolus não completou o 
estágio de larva, fato contrário do que ocorreu quando esse predador foi alimentado com dietas constituídas por pólen e por pólen mais ácaro rajado. A causa da morte de todos os indivíduos de A. herbicolus na fase de larva quando alimentado somente por $T$. urticae está ligado ao fato de que os indivíduos nesse estádio morreram emaranhados à teia formada pelas fêmeas do ácaro-rajado e não se relaciona com a qualidade nutricional da dieta oferecida. Segundo McMurtry et al. (1970) Amblyseius spp não se alimenta quando está na fase de larva. Isso seria vantajoso para a larva, pois a mesma não tem a necessidade de procurar alimento, juntando-se a isso a baixa capacidade que as mesmas apresentariam para capturar e consumir as presas.

Quando alimentado somente por pólen de mamona associado ao ácaro-rajado, $A$. herbicolus completou a fase juvenil em 9,19 e 7,78 dias aproximadamente. Esse período para a fase juvenil é muito maior do que o encontrado para A. longispinosus que completou a fase juvenil em 4,79 dias quando alimentado pelo ácaro fitófago Eotetranychus cendanai (Acari: Tetranychidae) (Thongtab et al. 2001). A diferença no período para completar a fase juvenil entre A. herbicolus e A. longispinosus pode por um lado estar relacionada com a eficiência do segundo em atingir a fase adulta em menor tempo se alimentando apenas pela presa. Por outro lado, há de se destacar que o fitófago E. cendanai produz uma teia bem menos densa que $T$. urticae o que facilita a predação sobre E. cendanai.

Na fase adulta, o período de sobrevivência de A. herbicolus foi maior quando esse predador foi alimentado com a dieta 1 em relação à dieta 3. porém, contraditoriamente, maior taxa de oviposição diária e total foi obtida quando A. herbicolus foi alimentado pela dieta 3. Isso demonstra que a dieta somente à base de pólen provem energia para que A. herbicous sobreviva por maior tempo, mas essa sobrevivência não corresponde à maior taxa reprodutiva 
desse predador que foi obtida pela união de dietas à base de pólen e T. urticae. Os resultados obtidos neste trabalho indicam que $A$. herbicolus preda $T$. urticae somente após atingir a fase adulta, contudo esse fitófago não pode ser considerado um alimento adequado para o predador quando oferecido isoladamente, ou quando oferecido para o predador ainda na fase jovem.

McMurtry y Croft (1997) consideram A. herbicolus como generalista do tipo III, que pode se aproveitar de vários tipos de alimento, incluindo diferentes espécies de ácaros fitófagos, alguns pequenos insetos, pólen e substâncias açucaradas.

\section{CONCLUCOES}

- Em plantios de morangueiro, predadores generalistas podem encontrar diversas fontes de alimento como pólen e secreções açucaradas de insetos sugadores.

- Junto dessas fontes alternativas de alimento o predador, possivelmente, também se alimenta de formas jovens de T. urticae que são capturadas com maior facilidade quando estão fora do emaranhado de teias produzido pelos ácaros adultos.

- Ambliseius herbicolus não completa a fase jovem quando alimentado somente por $T$. urticae, mas os resultados aqui apresentados demonstram que a predação sobre esse fitófago é importante na fase adulta do predador.

- A associação desse predador com ácaros predadores especialistas deve ser futuramente estudada. 


\section{AGRADECIMENTOS}

Os autores agradecem ä CAPES, ao CNPq e ä FAPEMIG pelo suportes financeiros que propiciaram a realização deste trabalho, bem com a Universidade Federal de Vicosa representada pelo setor de Entomologia, local onde foram realizados todos os experimentos.

\section{REFERÊNCIAS}

Ali, F. 1998. Life tables of Phytoseiulus macropilis (Banks) (Gamasida: Phytoseiidae) at different temperatures. Experimental and Applied Acarology 22(8):335-342.

Badii, M., Hernandez-Ortiz, E., Flores, A. y Landeros, J. 2004. Prey stage preference and functional response of Euseius hibisci to Tetranychus urticae (Acari: Phytoseiidae, Tetranychidae). Experimental and Applied Acarology 34(3):263-273.

Bakker, F., Klein, M., Mesa, N. y Braun, A. 1993. Saturation deficit tolerance spectra of phytophagous mites and their phytoseiid predators on cassava. Experimental and Applied Acarology 17(2):97-113.

García-Marí, F. y González-Zamora, J. 1999. Biological control of Tetranychus urticae (Acari: Tetranychidae) with naturally occurring predators in strawberry plantings in Valencia, Spain. Experimental and Applied Acarology 23(6):487-495.

Helle, W. y Sabelis, M. 1985. Spider mites. Their biology, natural enemies and control, Elsevier, Amsterdam, 458p.

Krips, O., Witul, A., Willems, P.y Dicke, M. 1998. Intrinsic rate of population increase of the spider mite Tetranychus urticae on the ornamental crop gerbera: intraspecific variation in host plant and herbivore. Entomologia Experimentalis et Applicata 89(26):159-168.

McMurtry, J. y Croft, B. 1997. Life-styles of Phytoseiid mites and their roles in biological control. Annual Review of Entomology 42(1): 291-321.

McMurtry, J., Huffaker, C. y Van de Vrie, M. 1970. Ecology of tetranychid mites and their natural enemies: a review. I. Tetranychid enemies: their biological characteres and the impact of spray pratices. Hilgardia 40(11): 331-390.

Moraes, G., McMurtry, J., Denmark H. y Campos, C. 2004. A revised catalog of the mite family Phytoseiidae. Zootaxa 434:1- 494.

Moraes, G. 2002. Controle biológico de ácaros fitófagos com predadores, p.225-237. In J.R.P. Parra, P.S.M. Botelho, B.S. Corrêa-Ferreira \& J.M.S. Bento (eds.), Controle biológico no Brasil: Parasitóides e predadores. São Paulo, Manole, 635p.

Moraes, G. 1991. Controle biológico de ácaros fitófagos. Inf. Agropec. 15:53-55.

Opit, G., Nechols, J., Margolies, D. y Williams, K. 2005. Survival, horizontal distribution, and economics of releasing predatory mites (Acari: Phytoseiidae) using mechanical blowers. Biological Control 33(3): 344-351.

Osborne, L., Ehler, L. y Nechols, J. 1985. Biological control of the twospotted spider mite in greenhouses. Bulletin 853, Institute of Food and Agricultural Services, University of Florida, Gainesville, 40p. 
Reis, P., Teodoro, A., Neto, P. y Silva, E. 2007. Life history of Amblyseius herbicolus (Chant) (Acari: Phytoseiidae) on coffee plants. Neotropropical Entomology. Apr. 36 (2):282-287

Skirvin, D. y Williams, M. 1999. Differential effects of plant species on a mite pest (Tetranychus urticae) and its predator (Phytoseiulus persimilis): Implications for biological control. Experimental and Applied Acarology 23(2):497-512.

Shih, C. y Huang, J. Functional responses of Amblyseius womersleyi preying on the kanzawa spider mite. En: Dusbabek, F. y Bkva, V. (Ed.). Modern Acarology, Academia, Prague and SPB Academic Publishing bv, The Hague. p481-486.

Thongtab, T., Chandrapatya, A. y Baker, G. 2001. Biology and efficacy of the predatory mite, Amblyseius longispinosus (Evans) (Acari, Phytoseiidae) as a biological control agent of Eotetranychus cendanai Rimando (Acari, Tetranychidae). J. Appl. Entomol. 125(2):543-549.

Van Houten, Van Rijn, P., Tanigoshi, L., Van Stratum, P. y Bruin J. 1995. Pre-selection of predatory mites to improve year-round biological control ofwestern flower thrips in greenhouse crops. Entomol. Exp. Appl. 74(3):225-234.

Zhang, Z. y Sanderson, J. 1995. Twospotted spider mite (Acari: Tetranychidae) and Phytoseiulus persimilis (Acari: Phytoseiidae) on greenhouse roses: Spatial distribution and predator efficacy. J. Econ. Entomol. 88 (2): 352-357. 


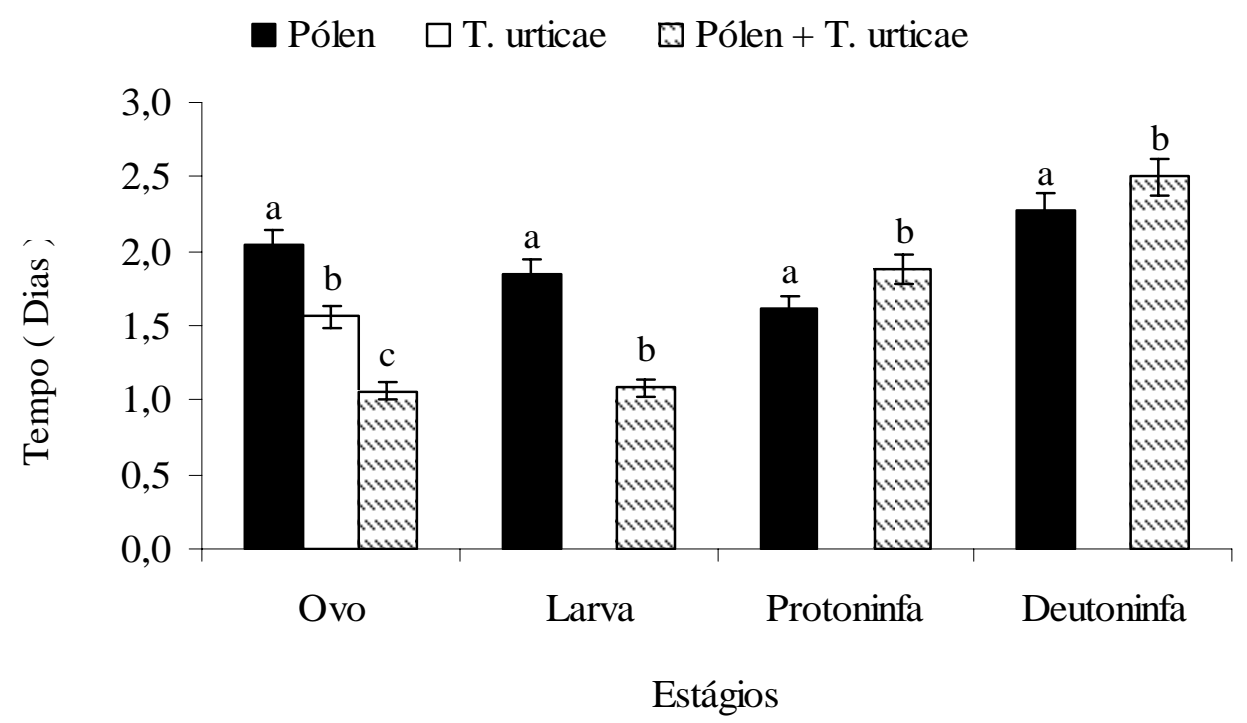

Figura 1. Longevidade em dias dos estágios imaturos de A. herbicolus em três dietas alimentares.

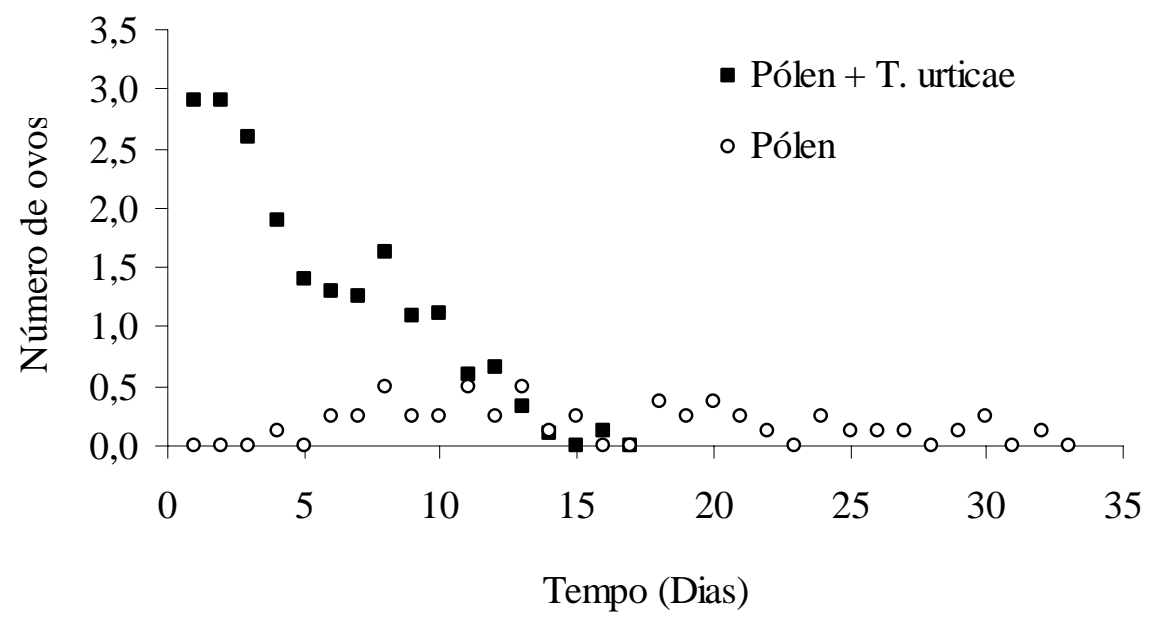

Figura 2. Taxa de oviposição do ácaro predador A. herbicolus em duas dietas alimentares. 


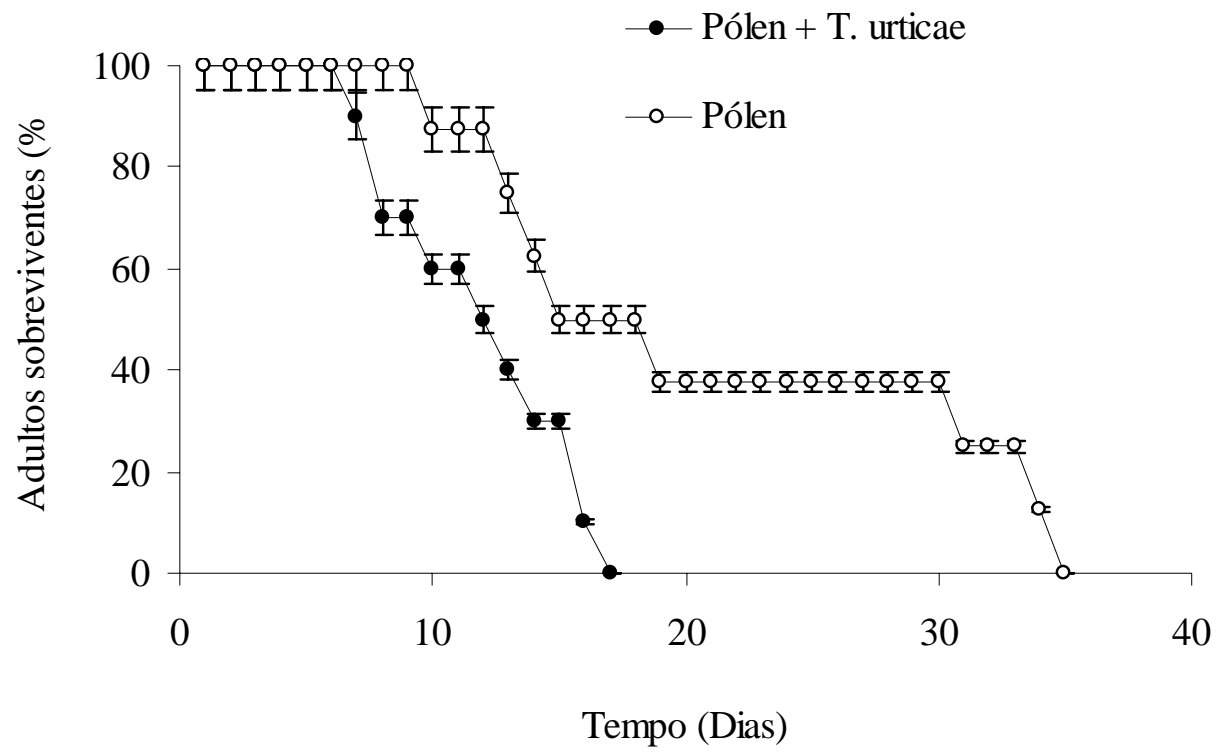

Figura. 3. Sobrevivência (\%) de adultos de A. herbicolus, em duas dietas alimentares. 